\title{
Detecção Rápida de Ceratocystis fimbriata em Lenho Infetado de Eucalipto, Mangueira e Outros Hospedeiros Lenhosos
}

\author{
Francisco A. Ferreira, Luis A. Maffia \& Evander A. Ferreira \\ Universidade Federal de Viçosa, Departamento de Fitopatologia, CEP 36571-000, Viçosa, MG
}

(Aceito para publicação em 07/07/2005)

Autor para correspondência: Francisco Alves Ferreira

FERREIRA, F.A., MAFFIA, L.A. \& FERREIRA, E.A. Detecção rápida de Ceratocystis fimbriata em lenho infetado de eucalipto, mangueira e outros hospedeiros lenhosos. Fitopatologai Brasileira 30:543-545. 20005.

\section{RESUMO}

Desenvolveu-se uma técnica de detecção rápida de Ceratocystis fimbriata em lenho de eucalipto (Eucalyptus spp.) infetado, visualizando-se clamidósporos (aleuroconídios) ao microscópio ótico comum, em vasos do xilema, medula e raios medulares, a partir de cortes histopatológicos à mão livre, feitos com lâmina de barbear, ao microscópio estereoscópico. O tempo médio gasto para a detecção do patógeno, do corte histopatológico tangencial à total visualização dos clamidósporos ao microscópio ótico comum, foi de 3,5 min e bem menos utilizando-se corte longitudinal passando pela medula, contra, no mínimo, quatro a cinco dias, usando-se outras técnicas como o isolamento em BDA, deposição de fragmentos de lenho doente entre fatias de cenoura usadas como isca, ou pedaços de lenhos doentes deixados em câmara úmida. Essa técnica histopatológica é também viável para a detecção do patógeno em outros hospedeiros lenhosos e, inclusive, para a detecção de hifas de Lasiodiplodia theobromae, mesmo quando esses dois fungos estavam num mesmo tecido, como na doença-complexo seca de mangueira investigada no Sultanato de Omã. Além de eucalipto, mangueira (Mangifera indica) e cacaueiro (Theobroma cacao) é provável que essa técnica possa ser estendida para outros hospedeiros lenhosos de C. fimbriata.

Palavras-chave adicionais: etiologia, doença fúngica.

\begin{abstract}
Rapid detection of Ceratocystis fimbriata in infected wood of eucalyptus, mango, and other woody hosts

A quick histopathological technique was developed to detect clamidospores (aleuroconidia) of Ceratocystis fimbriata in infected xylem vessels and medulla of eucalyptus (Eucalyptus spp.) wood using light microscopy, and tangential hand prepared cross sections made with razor blade under a stereoscopic microscope. The average time necessary to detect the pathogen, including sample preparation and microscope observations, was 3.5 min and less when longitudinal sections passing by the medulla were made. Therefore, this method was significantly quicker than other traditional techniques such as pathogen isolation on potato-dextrose-agar medium, deposition of infected wood fragments between slices of carrot bait, or placing the infected pieces of wood in a moist chamber. This technique also was viable to detect C. fimbriata colonizing other woody hosts such as cocoa (Theobroma cacao), mango (Mangifera indica), and hyphae of Lasiodiplodia theobromae even when both organisms were in the same tissue as investigated in the mango blight disease in the Sultanate of Oman.
\end{abstract}

Additional keywords: etiology, fungal disease.

Ceratocystis fimbriata Ellis \& Halsted é causador de doenças em muitas plantas lenhosas e em algumas herbáceas de importância econômica como, por exemplo, acácia negra (Acácia mearnsii De Wild), batata doce [Ipomoea batatas (L.) Lam], cacau (Theobroma cacao L.), cafeeiro (Coffea arabica L.), citrus (Citrus spp.), eucalipto (Eucalyptus spp.), figo (Ficus carica L.), gmelina (Gmelina arborea Roxb), mangueira (Mangifera indica L.) e seringueira [Hevea brasiliensis (Willd. ex Adr. de Juss.) Muell \& Arg]. Em planta lenhosa, C. fimbriata é um típico patógeno de xilema (Baker \& Harrington, 2004) cujo sintoma marcador é constatável nas secções transversais de órgãos lenhosos, na forma de estrias radiais escuras (Ferreira \& Milani, 2002), da medula para o exterior do lenho, ou da periferia do lenho para a medula, ou descoloração (mancha escura), do tipo cunha, em geral da periferia para a medula. Todavia, especialmente esse último sintoma pode advir de doença causada por Botryosphaeria Ces. \& De Not. (Baker \& Harrington, 2004) ou de Lasiodiplodia theobromae (Pat.) Griff \& Maubl. em vários hospedeiros lenhosos. Como exemplo, na doençacomplexo seca da mangueira ("mango blight disease"), no Sultanato de Omã, inspecionada, fitopatologicamente pelo primeiro autor, em 2001, em que o sintoma marcador ora associava-se a $C$. fimbriata ou a $L$. theobromae. A detecção de C. fimbriata a partir de xilema infetado dá-se, rotineiramente, a partir de pedaços de lenho afetado deixados em câmara úmida, ou transferindo fragmentos de lenho infetado para meio de cultura, como BDA ou similar (Ferreira, 1989), ou pela deposição de fragmentos de lenho doente entre fatias de cenoura usadas como isca (Baker \& Harrington, 2004), sendo que essa técnica de isca foi considerada seletiva, por Moller \& De Vay (1968), para a 
constatação de C. fimbriata. Com as técnicas citadas, o tempo mínimo básico para a constatação do patógeno é de quatro a cinco dias, sendo necessária a atividade vital do fungo.

Em situações em que o etiologista atua como consultor, fora de sua região de trabalho ou país, as diagnoses rápidas são geralmente desejáveis. Assim, desde que se teve a constatação da doença murcha de $C$. fimbriata em eucalipto no Sudeste da Bahia, em dezembro de 1997 (Ferreira, 1999), a possibilidade de se detectar o patógeno, num mais curto tempo, precisava ser tentada. Essa oportunidade emergiu com a visualização dos clamidósporos de $C$. fimbriata, na doença seca da mangueira, desenhados por Viégas (1960). Pela presumível função de resistência desses esporos, pensou-se que, talvez, eles pudessem ser detectados numa técnica histopatológica de detecção rápida, ao microscópico. Embora Viegas (1960) tenha advertido para não se buscar o patógeno no lenho de mangueira, os primeiros cortes histopatológicos, à mão livre, com lâmina de barbear, feitos em xilema de eucalipto infetado pelo patógeno, revelaram a presença dos clamidósporos (o mesmo que aleuroconidios, segundo Baker \& Harrigton, 2004), viabilizando a detecção rápida de C. fimbriata. Assim, a partir de hastes infetadas de três clones de eucalipto, com cerca de um ano de idade, e de brotações novas, doentes, de um dos clones em banco clonal, prepararam-se quatro lotes de cortes histopatológicos com lâmina de barbear nova, ao microscópio estereoscópico, tendo-se anotado o tempo gasto em cada lote, incluindo a constatação dos clamidósporos ao microscópio ótico comum. O tempo médio foi de 3,5 min, utilizando-se cortes tangenciais, com a constatação dos clamidósporos na medula, nos vasos e nos raios medulares (Figura 1 A e C). Portanto, esse tempo é muito rápido considerando-se o mínimo de quatro a cinco dias quando se utilizam as outras técnicas de detecção do patógeno. Durante as inspeções rotineiras da doença, em material de eucalipto dos estados da Bahia, Mato Grosso do Sul, Minas Gerais e São Paulo, dezenas de cortes longitudinais foram também feitos passando pela medula. Embora o tempo gasto com esse tipo de corte seja bem menor do que os tangenciais, não se fez a monitoração do seu respectivo tempo, porque nem sempre é possível utilizá-los, em decorrência da infestação do parênquima medular por fungos saprófitas, como Aspergilus spp. e Penicillium spp. e outros fungos contaminantes. Uma grande vantagem dessa técnica de detecção rápida de $C$. fimbriata é não ser afetada pela morte do patógeno no lenho e pelas contaminações microbianas, comuns nos meios de agar e na isca de cenoura. Por outro lado, ela tem a desvantagem de não se poder manipular as estruturas do fungo num meio de cultura ou numa isca de cenoura. No tocante à morte de C. fimbriata no lenho, essa técnica histopatológica permite ter a confir

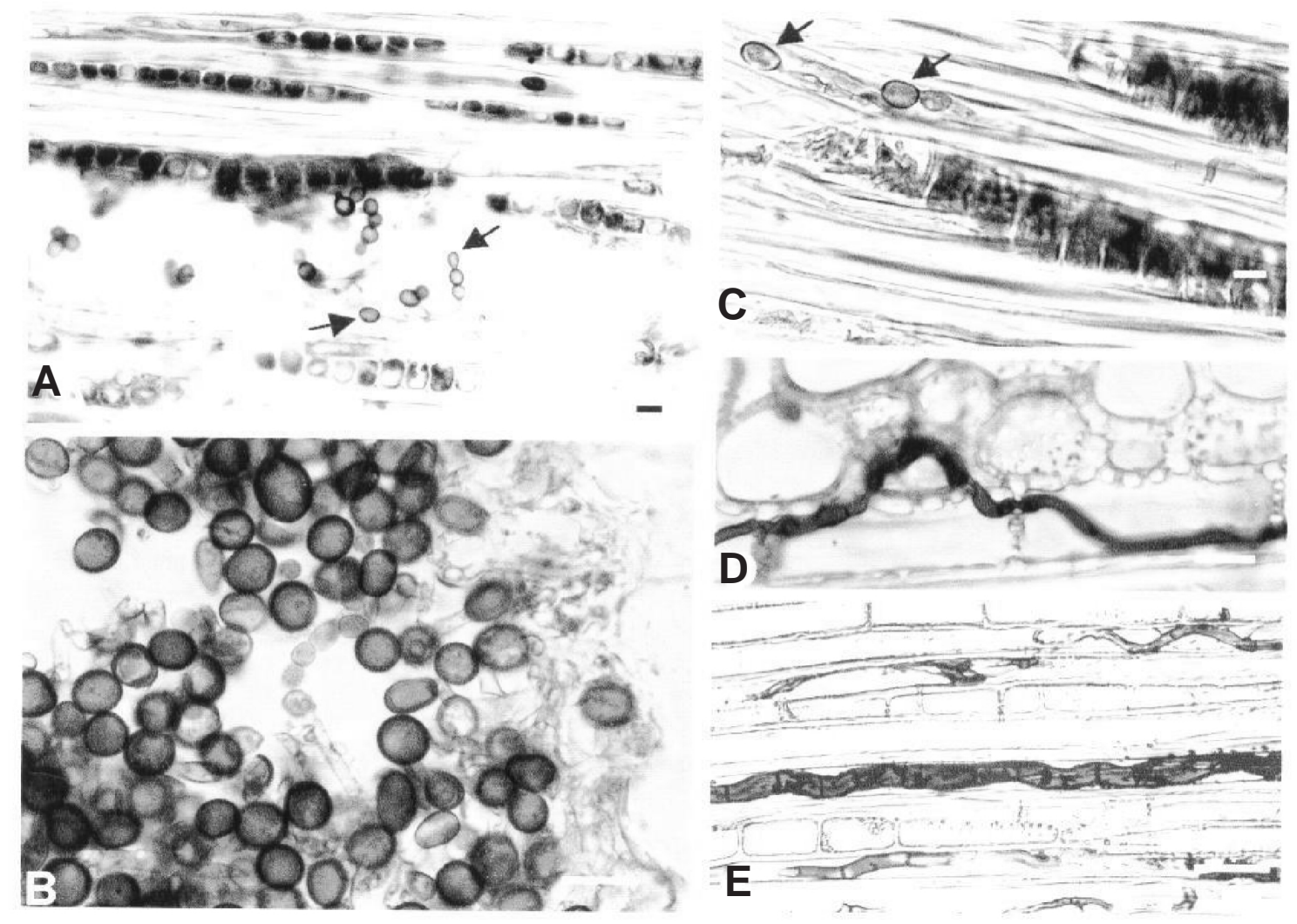

FIG. 1 - Clamidósporos de Ceratocystis fimbriata em A, B e C, respectivamente em vasos, medula e raio medular. Em D, e E, hifas de Lasiodiplodia theobroamae respectivamente em xilema de conífera e de seringueira (Hevea brasiliensis) (barras de escala $=10 \mu \mathrm{m})$. 
mação do seu envolvimento etiológico por um tempo maior, possibilitando uma diagnose que não seria possível a um diagnosticador atuando mais tardiamente, utilizando-se das outras técnicas que envolvem o seu crescimento. Essa técnica histopatológica, consiste na realização de cortes, à mão livre, com lâmina de barbear nova, ao microscópio estereoscópico, preferentemente longitudinais e, quando possível, passando pelo parênquima medular e, secundariamente, com cortes tangenciais. Os cortes montados em gotas de corante azul de algodão em lactofenol, em lâminas para microscopia, e cobertos por lamínula, são aquecidos em chama, até o início de fervura, seguindo-se o exame ao microscópio, com ocular 10X e objetiva de 40X. Os clamidósporos, simples ou em cadeias, são observáveis dentro de vasos (Figura 1A), no parênquima medular (Figura 1 B), e nos raios medulares (Figura 1C), sendo mais facilmente constatados trabalhando-se com o diafragma do microscópio quase totalmente aberto. Dada a rapidez do resultado obtido com o emprego desta técnica histopatológica, o seu uso é recomendável para auxiliar levantamento de unidades de plantas ou de órgãos infetados por $C$. fimbriata e para se ter a definição da presença ou ausência do patógeno. Uma situação real em que essa técnica revelou-se valiosíssima, deu-se no Sultanato de Omã, quando o primeiro autor lidou com a participação simultânea de $C$. fimbriata e Lasiodiplodia theobromae num complexo de doença em mangueira, denominado seca da mangueira ("mango blight disease"), em que, visualmente, não se distinguia, que sintoma no lenho relacionava-se a $C$. fimbriata ou a $L$. theobromae. Isso deixou de ser dúvida com a aplicação dessa técnica histopatológica, que detecta também hifas de $L$. theobromae, tanto em lenho de folhosas quanto em coníferas (Figura 1 D e E). É provável que a técnica ora descrita para detecção rápida de $C$. fimbriata em eucalipto e mangueira possa também ser estendida a outros hospedeiros lenhosos, conforme teste bem sucedido de sua aplicação em cacaueiro, feito por J. L. Bezerra (informação pessoal de J.L. Bezerra, CEPLAC, BA).

\section{REFERÊNCIAS BIBLIOGRÁFICAS}

BAKER, C.J. \& HARRINGTON, T.C. Ceratocystis fimbriata. Surrey, England, CABI Publishing, 2004.

FERREIRA, F.A. \& MILANE, D. Diagnose visual e controle de doenças abióticas e bióticas do eucalipto no Brasil. International Paper, Mogi-Guaçu, 2002.

FERREIRA, F.A. Patologia Florestal - Principais doenças doenças florestais no Brasil. SIF, UFV, Viçosa, 1989.

FERREIRA, F.A., DEMUNER, A.M., DEMUNER, M.L. \& PIGATO, S. Murcha de Ceratocystis em eucalipto no Brasil. Fitopatologia Brasileira 24:284. 1999. (Resumo)

MOLLER, W.J. \& De VAY, J. Carrot as a species-selective isolation medium for Ceratocystis fimbriata. Phytopathology 58:123-124. 1968.

VIEGAS, A.P. Seca da mangueira. Bragantia 19:163-182. 1960. 